\title{
ATP content and viability of spermatozoa drive variability of fertilization success in the Pacific oyster (Crassostrea gigas)
}

\author{
Boulais Myrina ${ }^{1,{ }^{*}}$, Soudant Philippe ${ }^{2}$, Le Goïc Nelly ${ }^{2}$, Quéré Claudie ${ }^{3}$, Boudry Pierre ${ }^{3}$, Suquet Marc ${ }^{1}$ \\ ${ }^{1}$ Ifremer, UMR 6539 LEMAR (UBO-CNRS-IRD-Ifremer), Site Expérimental d'Argenton, Landunvez, \\ France \\ ${ }^{2}$ IUEM, UMR 6539 LEMAR (UBO-CNRS-IRD-Ifremer), Université de Bretagne Occidentale, Plouzané, \\ France \\ ${ }^{3}$ Ifremer, UMR 6539 LEMAR (UBO-CNRS-IRD-Ifremer), Centre de Bretagne, Plouzané, France \\ *Corresponding author : Myrina Boulais, email addresses : Myrina.Boulais@ifremer.fr ; \\ myrina.boulais@gmail.com
}

\begin{abstract}
:
Fertilization of the oocyte is a critical process of sexual reproduction depending among other factors on spermatozoa functionality. Mitochondria participate in many crucial processes for spermatozoa motility and fertilizing ability. The Pacific oyster, Crassostrea gigas, is characterized by a high inter-individual variability of its reproductive success which has been shown to be partially due to the variability of gamete quality. The present study explored spermatozoa characteristics such as: i) relationships among mitochondrial functionality (ATP content, mitochondrial membrane potential (MMP), reactive oxygen species production); sperm viability (percentages of live, dying, and dead); and motility; and ii) their involvement in inter-oyster variability of fertilizing ability demonstrated using simple and multiple regressions. Our results showed that ATP content depends on both MMP and viability of spermatozoa. Using multiple regressions, $61 \%$ of the variability of the trochophore-larval yield was explained by a model combining the ATP content and the percentage of dying spermatozoa $(P<0.001)$. Our results reveal that capacity of spermatozoa to maintain a high level of ATP via OXPHOS partly explains the inter-individual variability of fertilization success in the Pacific oyster. Sperm ATP content and viability assays will provide valuable tools for assessing sperm quality of this species in aquaculture production, cryopreservation, and bioassays.
\end{abstract}

\section{Highlights}

- Control of gamete quality is crucial for aquaculture. No proxy to assess sperm quality in bivalves. Variability of gamete quality in the Pacific oyster ATP and viability are sperm quality markers in the Pacific oyster.

Keywords : Spermatozoa, Quality, Motility, Viability, ATP content, ROS production 


\section{Introduction}

Fertilization of oocytes is a critical process of sexual reproduction depending among other factors on spermatozoa functionality. Motility of the male gamete allows spermatozoa to actively reach and penetrate oocytes. Because flagellar movement occurs through a reaction catalyzed by dynein-ATPases located in the flagellum (Cosson, 1996), adenosine triphosphate (ATP) is needed to fuel the spermatozoa movement phase.

Mitochondria are double-membrane organelles that participate in the synthesis of ATP via oxidative phosphorylation (OXPHOS). OXPHOS is supported by the mitochondrial membrane potential (MMP) resulting from the electrochemical gradient of protons across the inner mitochondrial membrane, and allowing the ATP-synthase to phosphorylate ADP to ATP. Besides its involvement in ATP synthesis, mitochondria are also a source of intracellular reactive oxygen species (ROS) production in spermatozoa (Koppers et al., 2008). ROS are functionally important in spermatozoa physiology. Low and regulated concentrations of ROS play a role in promoting fully activated motility (forward translation and efficient flagellar beat) and acrosomal exocytosis (de Lamirande et al., 1997; Ford, 2004). Mitochondria also participate in various cellular functions, such as calcium homeostasis and the intrinsic apoptotic pathway (Amaral et al., 2013). Finally, mitochondrial dysfunction (i.e., defects in mitochondrial ultrastructure, genome, transcriptome or proteome, low MMP, altered oxygen consumption) has been linked with loss of spermatozoa functionality (Amaral et al., 2013).

Broadcast spawning is commonly observed in marine species, where external fertilization requires the synchronous release of spermatozoa and oocytes. Spermatozoa are motile for a few minutes to hours, depending on species (Demoy-Schneider et al., 2012; Mita et al., 1994a, 1994b; Suquet et al., 2013). Intracellular ATP content (ATP content) results from ATP accumulated during spermatozoa maturation in the gonad and from ATP produced 
via OXPHOS (Boulais et al., 2015; Demoy-Schneider et al., 2012, 2014; Mita and Nakamura, 1998). ATP level is a key factor for spermatozoa motility and fertilizing ability. A decline of the ATP content is recorded after motility activation of spermatozoa, which leads to the end of movement in sea urchins, and the king scallop, Pecten maximus (Christen et al., 1983; Mita and Yasumasu, 1983; Mita et al., 1994c; Mohri, 1958; Suquet et al., 2013; Taguchi et al., 1963). Finally, ATP level also sustains fertilizing ability, acrosomal exocytosis and binding to the oocytes in spermatozoa of the sea urchins (Christen et al., 1986; Hirohashi and Lennarz, 1998).

Involvement of other characteristics related to mitochondrial functionality (i.e., MMP, ROS production) in viability, motility and fertilizing ability of spermatozoa have been little documented. In the Eastern oyster, Crassostrea virginica, spermatozoa viability and MMP are important for motility and fertilizing ability (Paniagua-Chavez et al., 2006). In the sea urchins, Anthocidaris crassispina and Hemicentrotus pulcherrimus, excessive production of ROS in spermatozoa leads to reduced motility and fertilizing ability (Kazama et al., 2012).

The Pacific oyster, Crassostrea gigas, is characterized by a high inter-individual variability of its reproductive success which is partially due to the variability of gamete quality (Boudry et al., 2002). Consequently, the evaluation and control of sperm quality are essential to improve aquaculture production (e.g., controlled crosses, selective breeding) and sperm cryobanking, and to assess the quality of sperm for ecophysiology and ecotoxicology bioassay work with this species. To date, only a small panel of criteria is used to assess sperm quality in bivalves, mainly based on visual observations of sperm motility and concentration. These assays based on microscope observations often have little predictive value and can be subjective according to each observer. In the Pacific oyster, it has been demonstrated that via OXPHOS, mitochondria produce a high level of ATP required to sustain the movement phase (i.e., over 24 h) (Boulais et al., 2015). However, the involvement of cellular characteristics 
related to mitochondrial functionality (i.e., ATP content, MMP, ROS production), viability (percentages of live, dying, and dead) and motility in fertilizing ability of spermatozoa remained to be explored. In the present study, involvement of these characteristics in spermatozoa functionality and inter-oyster variability of fertilization success were investigated using simple and multiple regressions in 20 individual male Pacific oysters.

\section{Materials and methods}

\subsection{Sperm collection}

During the natural reproduction period (June), three-year old Pacific oysters were collected from aquaculture stock in the Bay of Brest (Finistère, France). Since our study aimed at studying spermatozoa biological characteristics of ripe oysters, only stage 3 (i.e., ripe gonad) males were selected $(n=20)$ (Steele and Mulcahy, 1999). Sperm was collected for each oyster by stripping gonads. Briefly, gonads were incised and spermatozoa were collected in $10 \mathrm{~mL}$ of sea water at $19^{\circ} \mathrm{C}$ and filtered at $1 \mu \mathrm{m}$ (FSW). The resulting sperm suspensions were sieved through $60 \mu \mathrm{m}$ mesh. Concentrations of spermatozoa were determined in duplicates by flow cytometry according to Le Goïc et al. (2013), and were adjusted to 7 x $10^{8}$ spermatozoa $\mathrm{mL}^{-1}$ by further dilution in FSW, in $20 \mathrm{~mL}$ plastic vials.

Assessments of spermatozoa cellular characteristics (relative cell size and complexity, MMP, ROS production, viability, percentage of motile spermatozoa and velocity), ATP content and fertilization success were conducted $1 \mathrm{~h}$ post incubation in FSW and at $19{ }^{\circ} \mathrm{C}$.

\subsection{Characterization of spermatozoa movement}

Movement features were recorded as described in Boulais et al. (2015). Briefly, spermatozoa were diluted 20 times in FSW containing $1 \mathrm{~g} \mathrm{~L}^{-1}$ of bovine serum albumin (BSA). Then, $7 \mu \mathrm{L}$ of diluted sperm suspension were transferred to a Fast-Read ${ }^{\circledR}$ cell 102 (Fisher Scientific) and 
spermatozoa movement characteristics were recorded using a microscope (dark field, Olympus BX51, 203 magnification), connected to a video camera (Qicam Fast 1394, 60 frames $\sec ^{-1}$ ). The percentage of motile spermatozoa and their velocity (VAP: velocity of the average path) were assessed using a computer-assisted sperm analyzer (CASA) plug-in developed for Image $\mathbf{J}$ software (Wilson-Leedy and Ingermann, 2007) and adapted to Pacific oyster spermatozoa (Boulais et al., 2015).

\subsection{Estimation of relative cell size and complexity, viability, mitochondrial membrane potential and ROS production}

Flow cytometric (FCM) analyses of spermatozoa relative size and complexity, viability, MMP, and ROS production were performed according to Le Goïc et al. (2013) using an EasyCyte Plus cytometer (Guava Millipore) equipped with standard optics and a $488 \mathrm{~nm}$ argon laser.

Viability was measured using a 10-min dual staining with SYBR-14 (final concentration: $1 \mu \mathrm{M}$ ) and propidium iodide (PI; final concentration: $10 \mu \mathrm{g} \mathrm{mL}^{-1}$ ) on $200-\mu \mathrm{L}$ samples at $10^{6}$ spermatozoa $\mathrm{mL}^{-1}$ (Live/Dead Sperm Viability kit, Molecular Probes). Populations of live (labelled with SYBR-14 only, cells with intact plasma membranes), dying (labelled with SYBR-14 and PI, cells with damaged plasma membranes) and dead (labelled with PI only) spermatozoa were estimated for each male by drawing three regions on the cytogram of SYBR-14 and PI fluorescences. Results were expressed as percentages of live, dying and dead spermatozoa. Values from FSC (Forward Scatter: relative cell size) and SSC (Side Scatter: relative cell complexity) detectors were also acquired to estimate morphologic parameters of spermatozoa.

Spermatozoa MMP was measured using the potential-dependent JC-1 (Interchim FP52314A). JC-1 enters mitochondria and reversibly change color from green to orange as the 
MMP increases. Spermatozoa suspension at $10^{7}$ cells $\mathrm{mL}^{-1}(200-\mu \mathrm{L}$ sample) was incubated with JC-1 at a final concentration of $5 \mu \mathrm{M}$. After a 10-min incubation time, sample was diluted ten times in FSW to reach probe equilibrium. MMP was then estimated by the orange/green fluorescence ratio measured on the FCM.

Production of ROS was measured after a $30-\mathrm{min}$ incubation of spermatozoa $(200-\mu \mathrm{L}$ samples, $10^{6}$ spermatozoa $\mathrm{mL}^{-1}$ ) with $2^{\prime} 7^{\prime}$-dichlorofluorescein diacetate (DCFH-DA, Molecular probes, Invitrogen) at a final concentration of $10 \mu \mathrm{M}$. Inside cells, the diacetate radical is first hydrolyzed by esterase enzymes to form DCFH, which turns to highly green fluorescent 2',7'-dichlorofluorescein (DCF) upon oxidation by ROS. The DCF green fluorescence $(525 \mathrm{~nm})$, detected on the FCM, is proportional to the ROS production.

\subsection{Quantification of ATP content}

Intracellular ATP content of spermatozoa was estimated as described in Boulais et al. (2015). Briefly, for each male $5 \times 10^{6}$ spermatozoa in $500 \mu \mathrm{L}$ FSW were transferred in a $2 \mathrm{~mL}$ cryotube $\left(\mathrm{Nunc}^{\mathrm{TM}}\right)$, and stored in liquid nitrogen until later analysis. ATP content was assessed in triplicates by bioluminescence (kit ATPlite, Perkin Elmer) using a plate reader (EnSpire $^{\mathrm{TM}} 2300$ Multilabel Reader, PerkinElmer).

\subsection{Estimation of fertilizing ability}

Spermatozoa fertilizing ability was estimated using a common pool of oocytes collected from five ripe females. Oocytes were collected by gonad stripping, enumerated and fertilized according to Song et al. (2009), except the spermatozoa to oocyte ratio. A limiting spermatozoa to oocyte ratio of 100 was used to allow sperm fertilizing ability assessment. For each male, triplicate batches of 25000 oocytes were fertilized in $50 \mathrm{~mL}$ FSW. After $30 \mathrm{~min}$ of contact between spermatozoa and oocytes, beakers were filled up to $1.8 \mathrm{~L}$ with FSW for 
incubation $\left(19{ }^{\circ} \mathrm{C}\right)$. To estimate the fertilizing ability (number of trochophore larvae/number of oocytes), the number of trochophore larvae was enumerated $24 \mathrm{~h}$ after fertilization: each beaker was concentrated on $40 \mu \mathrm{m}$ mesh and transferred into a $10-\mathrm{mL}$ graduated cylinder. Trochophore larvae were enumerated by microscopic counts $(3 \times 50 \mu \mathrm{L})$, adding a few drops of formalin-free fixative (RCL2 ${ }^{\circledR}$, Alphelys) to prevent their movement.

\subsection{Statistical analyses}

Data are presented as mean \pm confidence interval (CI95\%) (coefficient of variation, CV\%). Data expressed as a rate or percentage were arcsine square root transformed before further analyses. Significant $(P<0.05)$ relationships between spermatozoa characteristics and then with the trochophore-larval yield were investigated using simple and multiple regressions, and quantified using the coefficient of determination $\left(\mathrm{R}^{2}\right)$. Statistical analyses were performed using Statgraphics software.

\section{Results}

Morphological parameters (FSC and SSC) showed a low variability among the 20 oysters (Table 1). A high percentage of live spermatozoa was observed (mean \pm CI95\%: $89.2 \pm 3.3$ ). Percentage of dead spermatozoa did not reach values higher than 5\%. However, this parameter showed high inter-oyster variability (Table 1). Similarly, values of percentage of dying spermatozoa, ATP content, and trochophore-larval yield were very different among oysters.

\section{Table 1}

Mean values of cellular characteristics and ATP content of spermatozoa, and of the trochophore-larval yield obtained when using spermatozoa from individual males of the 
Pacific oyster. Results are expressed as mean \pm CI95\% (CV \% $)(n=20$ oysters, except $n=18$ for ROS production and ATP content).

\begin{tabular}{lc}
\hline Feature & Mean \pm CI95\% (CV\%) \\
\hline FSC: Relative cell size & $63.7 \pm 3.4(12.3)$ \\
SSC: Relative cell complexity & $75.2 \pm 3.7(11.2)$ \\
Live spermatozoa (\%) & $89.2 \pm 3.3(8.4)$ \\
Dying spermatozoa (\%) & $6.6 \pm 2.6(87.2)$ \\
Dead spermatozoa (\%) & $2.2 \pm 0.7(77.6)$ \\
Mitochondrial Membrane Potential & $4.3 \pm 0.4(19.8)$ \\
(orange/green fluorescence ratio) & \\
ROS production (green fluorescence) & $32.5 \pm 4.2(28.0)$ \\
ATP content & $157.2 \pm 36.5(49.2)$ \\
(nmol 10-9 spermatozoa) & \\
Motile spermatozoa (\%) & \\
\hline
\end{tabular}

Using simple regression, percentage of motile spermatozoa had a positive linear relationship with velocity $\left(\mathrm{R}^{2}=0.56, P<0.001\right.$, Fig. 1 A), and a negative relationship with percentage of dead spermatozoa $\left(\mathrm{R}^{2}=0.33, P<0.01\right.$, Fig. $\left.1 \mathrm{~B}\right)$. ATP content was positively correlated to $\mathrm{MMP}\left(\mathrm{R}^{2}=0.23, P<0.05\right.$, Fig. $\left.2 \mathrm{~A}\right)$ and to percentage of live spermatozoa $\left(\mathrm{R}^{2}=\right.$ 
$0.58, P<0.001$, Fig. $2 \mathrm{~B})$. ATP content was negatively related to percentages of dying $\left(\mathrm{R}^{2}=\right.$ $0.50, P<0.001$, Fig. $2 \mathrm{C})$ and dead $\left(\mathrm{R}^{2}=0.36, \mathrm{p}<0.001\right.$, Fig. 2D) spermatozoa.

Trochophore-larval yield had a positive relationship with ATP content $\left(\mathrm{R}^{2}=0.40, P<\right.$ 0.01 , Fig. 3A) and percentage of live spermatozoa $\left(\mathrm{R}^{2}=0.55, P<0.001\right.$, Fig. 3B $)$, and a negative relationship with percentage of dying spermatozoa $\left(\mathrm{R}^{2}=0.57, P<0.001\right.$, Fig. $\left.3 \mathrm{C}\right)$.

Using multiple regressions, $61 \%(P<0.001)$ and $60 \%(P<00.1)$ of the variability of trochophore-larval yield was explained by a model combining ATP content and percentage of dying spermatozoa, and a model combining ATP content and percentage of live spermatozoa, respectively.

\section{Discussion}

In the present study, involvement of cellular characteristics, ATP content, and motility in spermatozoa functionality and in inter-oyster variability of fertilization success were investigated.

Motility of spermatozoa depends on sperm maturation, defined as the ability for spermatozoa to become ready for motility initiation, prior to collection by stripping or spawning (Demoy-Schneider et al., 2014). In the present work, the positive correlation obtained between percentage of motile spermatozoa and their velocity suggests that spermatozoa velocity may be related to maturation processes during spermatogenesis. This could be explained by the accumulation of several compounds during spermatogenesis, such as cyclic adenosine monophosphate (cAMP) or some ions, which are crucial for induction of flagellar beat (Demoy-Schneider et al., 2014). Percentages of motile spermatozoa were variable among the 20 oyster studied (mean \pm CI95\% (CV\%): $73.4 \pm 6.7 \%$ (21.0)) despite incubation of spermatozoa for $1 \mathrm{~h}$ in FSW to undergo the motility activation process. Such variability among males may be related to differences in the timing of spermatozoa 
maturation. It has been reported that spermatogonia are found together with spermatozoa in ripe gonad of the Pacific oyster because their proliferation is continuous throughout the reproductive period (Franco et al., 2010).

Viability (live, dying, dead) of spermatozoa was not the main factor controlling their movement, as the percentage of dead spermatozoa did not reach values higher than $5 \%$, and percentages of dying and live spermatozoa were not correlated to percentage of motile spermatozoa. Additionally, ATP content was not involved in controlling the end of spermatozoa motility. Overall, these results are consistent with our previous study wherein the end of spermatozoa movement after $24 \mathrm{~h}$ of incubation in FSW did not result from their loss of viability or exhaustion of their ATP content (Boulais et al., 2015). Maintenance of ATP level during the spermatozoa movement phase distinguishes the Pacific oyster from other documented marine species exhibiting external fertilization. In the king scallop, sea urchins, the European sea bass Dicentrarchus labrax and the turbot Psetta maxima, faster consumption of ATP by dynein-ATPases compared to its production via OXPHOS is generally claimed as the main factor leading to spermatozoa arrest (Dreanno et al., 1999a, 1999b; Mita et al., 1994a; Mohri, 1958; Suquet et al., 2013). However, in Pacific oyster spermatozoa, OXPHOS allows maintenance of the ATP content during their movement phase (Boulais et al., 2015). Factors controlling the arrest in Pacific oyster spermatozoa movement are still unknown and need to be studied.

The limited relationship observed between ATP content and MMP $\left(\mathrm{R}^{2}=0.23\right)$ highlights that factors other than MMP contribute to the ATP content of spermatozoa. These factors include other key components of OXPHOS, such as electron transfer efficiency of the respiratory chain or the ATP-synthase activity, needed to phosphorylate ADP to ATP. In addition, ATP content assessed $1 \mathrm{~h}$ post activation may partly result from ATP storage (i.e., ATP accumulated during spermatogenesis) (Boulais et al., 2015; Suquet et al., 2010). ATP 
content of spermatozoa was highly variable among the 20 oysters studied, ranging from 34.5 up to $308.5 \mathrm{nmol} 10^{-9}$ spermatozoa. Values of ATP content were previously reported in spermatozoa of the Pacific oyster, from $44.7 \pm 2.0 \mathrm{nmol} 10^{-9}$ spermatozoa just before activation up to $185.6 \pm 15.7 \mathrm{nmol} 10^{-9}$ spermatozoa after $1 \mathrm{~h} 30$ of incubation in FSW (Boulais et al., 2015; Suquet et al., 2010). Overall, male individual variability of spermatozoa ATP content observed at $1 \mathrm{~h}$ post activation in FSW (this study) may be explained by i) OXPHOS functionality, which depends partially on MMP, and ii) ATP storage. Both explanations do not exclude each other and are possibly influenced by some differences in the timing and synchronicity of spermatozoa maturation.

Our results showed that ATP content is related to viability in spermatozoa of the Pacific oyster. In this species, it was suggested that ATP depletion via inhibition of the ATPsynthase prevents cell death in spermatozoa (Haberkorn et al., 2010) as reported for human germ cells (Erkkila et al., 2006). In addition, it has been reported that ATP level is a factor determining human cell death by apoptosis or necrosis: exhaustion of ATP inhibits apoptosis and induces necrotic cell death (Eguchi et al., 1997). ATP transports chemical energy within cells for metabolism but could also control sperm viability through several intracellular regulatory mechanisms. Further research is needed to better understand the observed relationships between ATP content and viability of spermatozoa.

Involvement of spermatozoa characteristics in sperm ability to fertilize oocytes, estimated by the trochophore-larval yield, was investigated in the present study. Values of trochophore-larval yield were highly variable between the 20 males studied, ranging from 5.6 up to $64.8 \%$. Our results showed that spermatozoa with a high ATP content are more likely to successfully fertilize oocytes. In sea urchins, a high ATP level is required for spermatozoa to fertilize oocytes (Christen et al., 1983, 1986). These authors suggested that the acrosomal reaction requires ATP and can be prevented when ATP is lacking. Finally, it was suggested 
that ATP content controls stability of the male gamete binding to the oocyte surface (Hirohashi and Lennarz, 1998). As in sea urchins, spermatozoa of the Pacific oyster must undergo acrosomal reaction to bind and penetrate oocytes (Demoy-Schneider et al., 2014). Thus, these processes probably depend on the ATP content of oyster spermatozoa during fertilization.

The fertilizing ability of spermatozoa also depends on their viability. Once spermatozoa viability is reduced, their ability to produce a normal trochophore larva is decreased. Studies reporting viability of spermatozoa (live, dying and dead spermatozoa) in relation to their fertilizing ability are scarce. Paniagua-Chavez et al. (2006) did not observe a relationship between fertilizing ability and viability of post-thaw spermatozoa. These authors suggested that this lack of correlation was due to the cryopreservation process, which may have led to structural damage of the acrosome and reduced fertilizing ability of spermatozoa, without impacting the plasma membrane. Until present, most of the studies have considered the effect of DNA damage on sperm quality. In the green-lipped mussel (Perna canaliculus) spermatozoa, a negative correlation between viability (PI/SYBR-14 dual staining) and DNA integrity (Sperm Chromatin Structure Assay) was observed (Smith et al. 2012). The integrity of gamete DNA is crucial for normal development of the resulting embryo (Lewis and Ford, 2012). A close negative relationship was previously reported between spermatozoa with DNA damage and fertilization rate in the Pacific oyster (Gwo et al., 2003). In the same species, it was suggested that DNA damage of gametes could be responsible for the negative effects observed on larval development (i.e., decrease in hatching rate, higher level of larval abnormalities, and delay in metamorphosis) and growth (Barranger et al., 2014). Potential relationships between viability and DNA damage of Pacific oyster spermatozoa would be of interest to address in the future. 
In our work, ROS production was not correlated to any other spermatozoa characteristics. This suggests that ROS production was not involved in the regulation of ATP content, motility, viability and quality of Pacific oyster spermatozoa incubated for $1 \mathrm{~h}$ in FSW. This lack of relationships is surprising because ROS play an important role in spermatozoa functionality of vertebrate and sea urchin species (de Lamirande et al., 1997; Ford, 2004; Kazama et al., 2012). Furthermore, in our study, MMP did not regulate ROS generation of Pacific oyster spermatozoa but this did not exclude a role of the mitochondrial respiration chain complexes in ROS generation. Further investigations are required to characterize ROS pathways and the involvement of mitochondrial respiratory chain complexes in ROS production in spermatozoa of the Pacific oyster. Finally, it is important to highlight that spermatozoa were not incubated under conditions stimulating oxidative stress. Such conditions might lead to different results.

In conclusion, decrease in spermatozoa viability or ATP content reduces their ability to successfully produce normal trochophore larvae but these relationships have to be clarified and further functionally explored. We propose that the purpose of maintaining a high level of ATP content during the hours-long movement phase of Pacific oyster spermatozoa (Boulais et al., 2015) is to ensure fertilization success of this species. Furthermore, we suggest that required high level of ATP in spermatozoa depends on both i) OXPHOS efficiency to continuously synthetize ATP and ii) energy stored as ATP during spermatozoa maturation in the gonad. Finally, this knowledge has practical application for assessing the quality of sperm used in aquaculture production, cryopreservation, and bioassays. 


\section{Acknowledgements}

The authors want to thank the staff of Ifremer's facilities in Argenton. We are particularly grateful to Elizabeth S. Darrow for proofreading. This work was partly supported by the European project ReproSeed (FP7-KBBE-2009-3), co-coordinated by J.L. Nicolas. M. Boulais was funded by a doctoral grant from Région Bretagne and Ifremer. 


\section{References}

Amaral, A., Lourenco, B., Marques, M., Ramalho-Santos, J., 2013. Mitochondria functionality and sperm quality. Reproduction 146, R163-174. http://dx.doi.org/10.1530/REP-13-0178

Barranger, A., Akcha, F., Rouxel, J., Brizard, R., Maurouard, E., Pallud, M., Menard, D., Tapie, N., Budzinski, H., Burgeot, T., Benabdelmouna, A., 2014. Study of genetic damage in the Japanese oyster induced by an environmentally-relevant exposure to diuron: evidence of vertical transmission of DNA damage. Aquat. Toxicol. 146, 93104. http://dx.doi.org/10.1016/j.aquatox.2013.10.032

Boudry, P., Collet, B., Cornette, F., Hervouet, V., Bonhomme, F., 2002. High variance in reproductive success of the Pacific oyster (Crassostrea gigas, Thunberg) revealed by microsatellite-based parentage analysis of multifactorial crosses. Aquaculture 204, 283-296. http://dx.doi.org/10.1016/S0044-8486(01)00841-9

Boulais, M., Soudant, P., Le Goïc, N., Quéré, C., Boudry, P., Suquet, M., 2015. Involvement of Mitochondrial Activity and OXPHOS in ATP Synthesis During the Motility Phase of Spermatozoa in the Pacific Oyster, Crassostrea gigas. Biol. Reprod. 93, 1-7. https://doi.org/10.1095/biolreprod.115.128538

Christen, R., Schackmann, R.W., Dahlquist, F.W., Shapiro, B.M., 1983. 31P-NMR analysis of sea urchin sperm activation. Reversible formation of high energy phosphate compounds by changes in intracellular pH. Exp. Cell Res. 149, 289-294. http://dx.doi.org/10.1016/0014-4827(83)90400-7

Christen, R., Schackmann, R.W., Shapiro, B.M., 1986. Ionic regulation of sea urchin sperm motility, metabolism and fertilizing capacity. J. Physiol 379, 347-365. 
Cosson, J., 1996. A moving image of flagella: news and views on the mechanisms involved in axonemal beating. Cell Biol. Int. 20, 83-94. http://dx.doi.org/10.1006/cbir.1996.0012

de Lamirande, E., Jiang, H., Zini, A., Kodama, H., Gagnon, C., 1997. Reactive oxygen species and sperm physiology. Rev. Reprod. 2, 48-54.

Demoy-Schneider, M., Leveque, A., Schmitt, N., Le Pennec, M., Cosson, J., 2012. Motility activation and metabolism characteristics of spermatozoa of the black-lip-pearl oyster Pinctada margaritifera var: cumingii (Jameson, 1901). Theriogenology 77, 53-64. http://dx.doi.org/10.1016/j.theriogenology.2011.07.014

Demoy-Schneider, M., Schmitt, N., Suquet, M., Labbe, C., Boulais, M., Prokopchuk, G., Cosson, J., 2014. Biological characteristics of sperm in two oyster species: the Pacific oyster, Crassostrea gigas, and the black-lip pearl oyster, Pinctada margaritifera, in: Erickson, B.T. (Eds.), Spermatozoa: Biology, Motility and Function and Chromosomal Abnormalities. Nova Science Publishers Inc., New York, pp. 15-74.

Dreanno, C., Cosson, J., Suquet, M., Seguin, F., Dorange, G., Billard, R., 1999a. Nucleotide content, oxidative phosphorylation, morphology, and fertilizing capacity of turbot (Psetta maxima) spermatozoa during the motility period. Mol. Reprod. Dev. 53, 230243. http://dx.doi.org/10.1002/(SICI)1098-2795(199906)53:2<230::AIDMRD12>3.0.CO;2-H

Dreanno, C., Cosson, J., Suquet, M., Cibert, C., Fauvel, C., Dorange, G., Billard, R., 1999b. Effects of osmolality, morphology perturbations and intracellular nucleotide content during the movement of sea bass (Dicentrarchus labrax) spermatozoa. J. Reprod. Fertil. 116, 113-125.

Eguchi, Y., Shimizu, S., Tsujimoto, Y., 1997. Intracellular ATP levels determine cell death fate by apoptosis or necrosis. Cancer Res. 57, 1835-1840. 
Erkkila, K., Kyttanen, S., Wikstrom, M., Taari, K., Hikim, A.P.S., Swerdloff, R.S., Dunkel, L., 2006. Regulation of human male germ cell death by modulators of ATP production. Am. J. Physiol. Endocrinol. Metab. 290, E1145-1154. http://dx.doi.org/10.1152/ajpendo.00142.2005

Ford, W.C.L., 2004. Regulation of sperm function by reactive oxygen species. Hum. Reprod. Update 10, 387-399. http://dx.doi.org/10.1093/humupd/dmh034

Franco, A., Jouaux, A., Mathieu, M., Sourdaine, P., Lelong, C., Kellner, K., Heude Berthelin, C., 2010. Proliferating cell nuclear antigen in gonad and associated storage tissue of the Pacific oyster Crassostrea gigas: seasonal immunodetection and expression in laser microdissected tissues. Cell Tissue Res. 340, 201-210. http://dx.doi.org/10.1007/s00441-009-0923-6

Gwo, J.C., Wu, C.Y., Chang, W.S.P., Cheng, H.Y., 2003. Evaluation of damage in Pacific oyster (Crassostrea gigas) spermatozoa before and after cryopreservation using comet assay. Cryo Letters 24, 171-180.

Haberkorn, H., Lambert, C., Le Goïc, N., Moal, J., Suquet, M., Guéguen, M., Sunila, I., Soudant, P., 2010. Effects of Alexandrium minutum exposure on nutrition-related processes and reproductive output in oysters Crassostrea gigas. Harmful Algae 9, 427-439. http://dx.doi.org/10.1016/j.hal.2010.01.003

Hirohashi, N., Lennarz, W.J., 1998. Sperm-egg binding in the sea urchin: a high level of intracellular ATP stabilizes sperm attachment to the egg receptor. Dev. Biol. 201, 270-279. http://dx.doi.org/10.1006/dbio.1998.8984

Kazama, M., Sato, T., Hino, A., 2012. Spontaneous generation of reactive oxygen species and effect on motility and fertilizability of sea urchin spermatozoa. Zygote 22, 246258. http://dx.doi.org/10.1017/S0967199412000445 
Koppers, A.J., De Iuliis, G.N., Finnie, J.M., McLaughlin, E.A., Aitken, R.J., 2008. Significance of mitochondrial reactive oxygen species in the generation of oxidative stress in spermatozoa. J. Clin. Endocrinol. Metab. 93, 3199-3207. https://doi.org/10.1210/jc.2007-2616

Le Goïc, N., Hégaret, H., Fabioux, C., Miner, P., Suquet, M., Lambert, C., Soudant, P., 2013. Impact of the toxic dinoflagellate Alexandrium catenella on Pacific oyster reproductive output: application of flow cytometry assays on spermatozoa. Aquat. Living Resour. 26, 221-228. https://doi.org/10.1051/alr/2013047

Lewis, C., Ford, A.T., 2012. Infertility in male aquatic invertebrates: a review. Aquat. Toxicol. 120-121, 79-89. http://dx.doi.org/10.1016/j.aquatox.2012.05.002

Mita, M., Nakamura, M., 1998. Energy metabolism of sea urchin spermatozoa: an approach based on echinoid phylogeny. Zoolog. Sci. 15, 1-10. http://dx.doi.org/10.2108/zsj.15.1

Mita, M., Yasumasu, I., 1983. Metabolism of lipid and carbohydrate in sea urchin spermatozoa. Mol. Reprod. Dev. 7, 133-144. http://dx.doi.org/10.1002/mrd.1120070205

Mita, M., Oguchi, A., Kikuyama, S., Desantis, R., Nakamura, M., 1994a. Ultrastructural study of endogenous energy substrates in spermatozoa of the sea urchin urchins Arbacia lixula and Paracentrotus lividus. Zoolog. Sci. 11, 701-705.

Mita, M., Oguchi, A., Kikuyama, S., Yasumasu, I., De Santis, R., Nakamura, M., 1994b. Endogenous substrates for energy metabolism in spermatozoa of the sea urchins Arbacia Zixula and Paracentrotus lividus. Biol. Bull. 186, 285-290.

Mita, M., Fujiwara, A., De Santis, R., Yasumasu, I., 1994c. High-energy phosphate compounds in spermatozoa of the sea urchins Arbacia lixula and Paracentrotus 
lividus. Comp. Biochem. Physiol. Part D 109, 269-275. http://dx.doi.org/10.1016/0300-9629(94)90129-5

Mohri, H., 1958. Adenosine triphosphatases of sea urchin spermatozoa. J. Fac. Sci. Univ. Tokyo Sec. IV 8, 307-315.

Paniagua-Chavez, C.G., Jenkins, J., Segovia, M., Tiersch, T.R., 2006. Assessment of gamete quality for the eastern oyster (Crassostrea virginica) by use of fluorescent dyes. Cryobiology 53, 128-138. http://dx.doi.org/10.1016/j.cryobiol.2006.05.001

Smith, J.F., Adams, S.L., McDonald, R.M., Gale, S.L., McGowan, L.T., Tervit, H.R., 2012. Cryopreservation of Greenshell $^{\mathrm{TM}}$ Mussel (Perna canaliculus) sperm. II. Effect of cryopreservation on fertility, motility, viability and chromatin integrity. Aquaculture 364-365, 322-328. http://dx.doi.org/10.1016/j.aquaculture.2012.08.039

Song, Y.P., Suquet, M., Quéau, I., Lebrun, L., 2009. Setting of a procedure for experimental fertilisation of Pacific oyster (Crassostrea gigas) oocytes. Aquaculture 287, 311-314. http://dx.doi.org/10.1016/j.aquaculture.2008.10.018

Steele, S., Mulcahy, M.F., 1999. Gametogenesis of the oyster Crassostrea gigas in southern Ireland. J. Mar. Biol. Assoc. U. K. 79, 673-686.

Suquet, M., Labbe, C., Brizard, R., Donval, A., Le Coz, J.R., Quere, C., Haffray, P., 2010. Changes in motility, ATP content, morphology and fertilisation capacity during the movement phase of tetraploid Pacific oyster (Crassostrea gigas) sperm. Theriogenology 74, 111-117. http://dx.doi.org/10.1016/j.theriogenology.2010.01.021

Suquet, M., Quere, C., Mingant, C., Lebrun, L., Ratiskol, D., Miner, P., Cosson, J., 2013. Effect of sampling location, release technique and time after activation on the movement characteristics of scallop (Pecten maximus) sperm. Aquat. Living Resour. 26, 215-220. https://doi.org/10.1051/alr/2013048 
Taguchi, S., Yasumasu, I., Mohri, H., 1963. Changes in the content of adenine nucleotides upon aerobic incubation of sea urchin spermatozoa. Exp. Cell Res. 30, 218-223.

Wilson-Leedy, J.G., Ingermann, R. L., 2007. Development of a novel CASA system based on open source software for characterization of zebrafish sperm motility parameters. Theriogenology 67, 661-672. http://dx.doi.org/10.1016/j.theriogenology.2006.10.003 


\section{Figure legends}

Fig. 1. The graphs represent significant linear relationships between cellular characteristics of spermatozoa ( $\mathrm{n}=20$ oysters, $P<0.05$ ). Percentage of motile spermatozoa (Motility) and their velocity (Velocity, A); and percentage of motile spermatozoa (Motility) and dead spermatozoa $(\mathrm{B})$.

Fig. 2. The graphs represent significant linear relationships between ATP content and cellular characteristics of spermatozoa $(\mathrm{n}=20$ oysters, except $\mathrm{n}=18$ for ATP content, $P<0.05)$. ATP content (ATP) and mitochondrial membrane potential (MMP, A); ATP content and percentage of live spermatozoa (B); ATP content and percentage of dying spermatozoa (C); and ATP content and percentage of dead spermatozoa (D).

Fig. 3. The graphs represent significant linear relationships between trochophore-larval yield and spermatozoa characteristics $(\mathrm{n}=20$ oysters, except $\mathrm{n}=18$ for ATP content, $P<0.05)$. Trochophore-larval yield and ATP content (ATP, A); Trochophore-larval yield and percentage of live spermatozoa (B); and trochophore-larval yield and dying spermatozoa (C). 

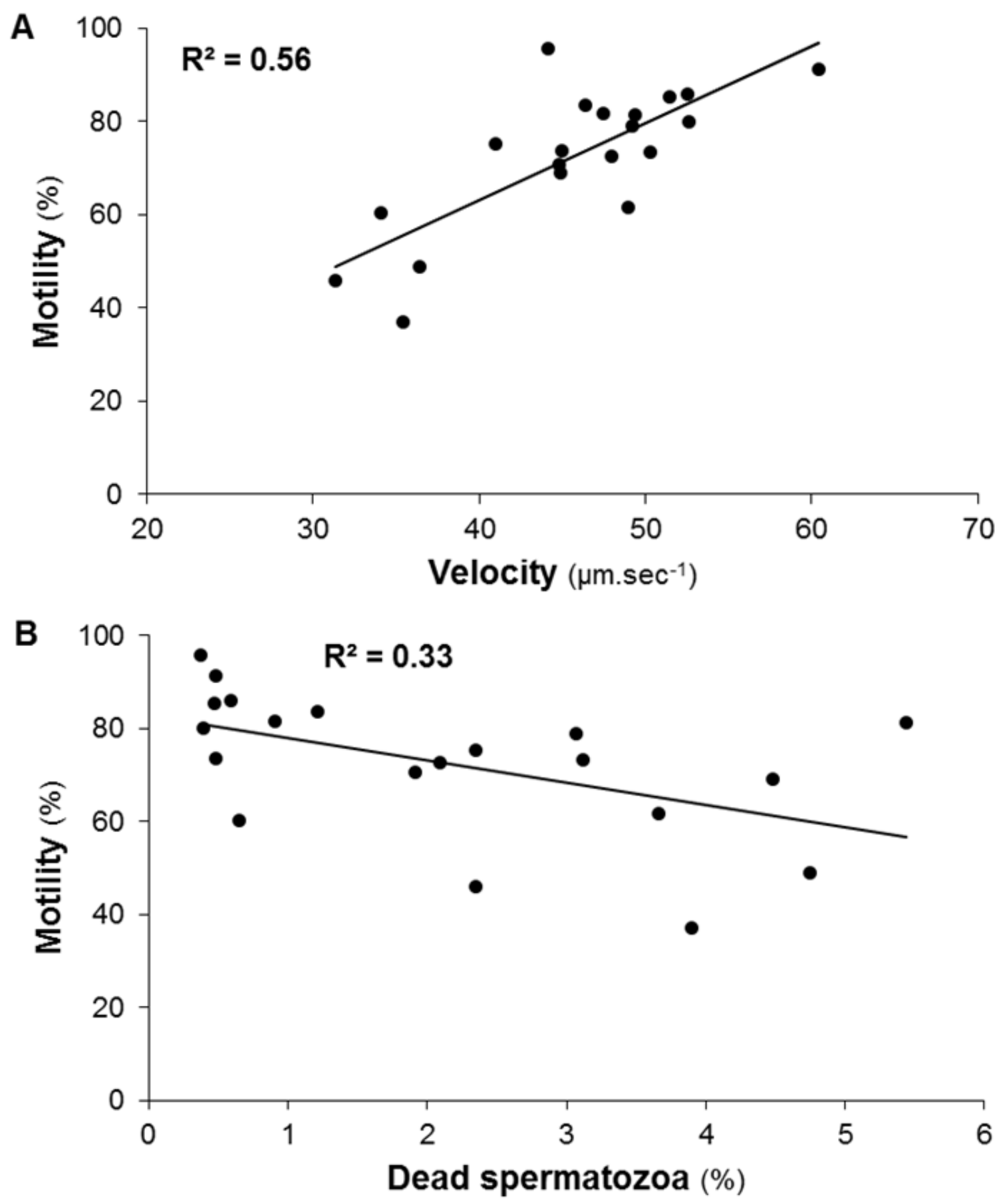

Figure 1 

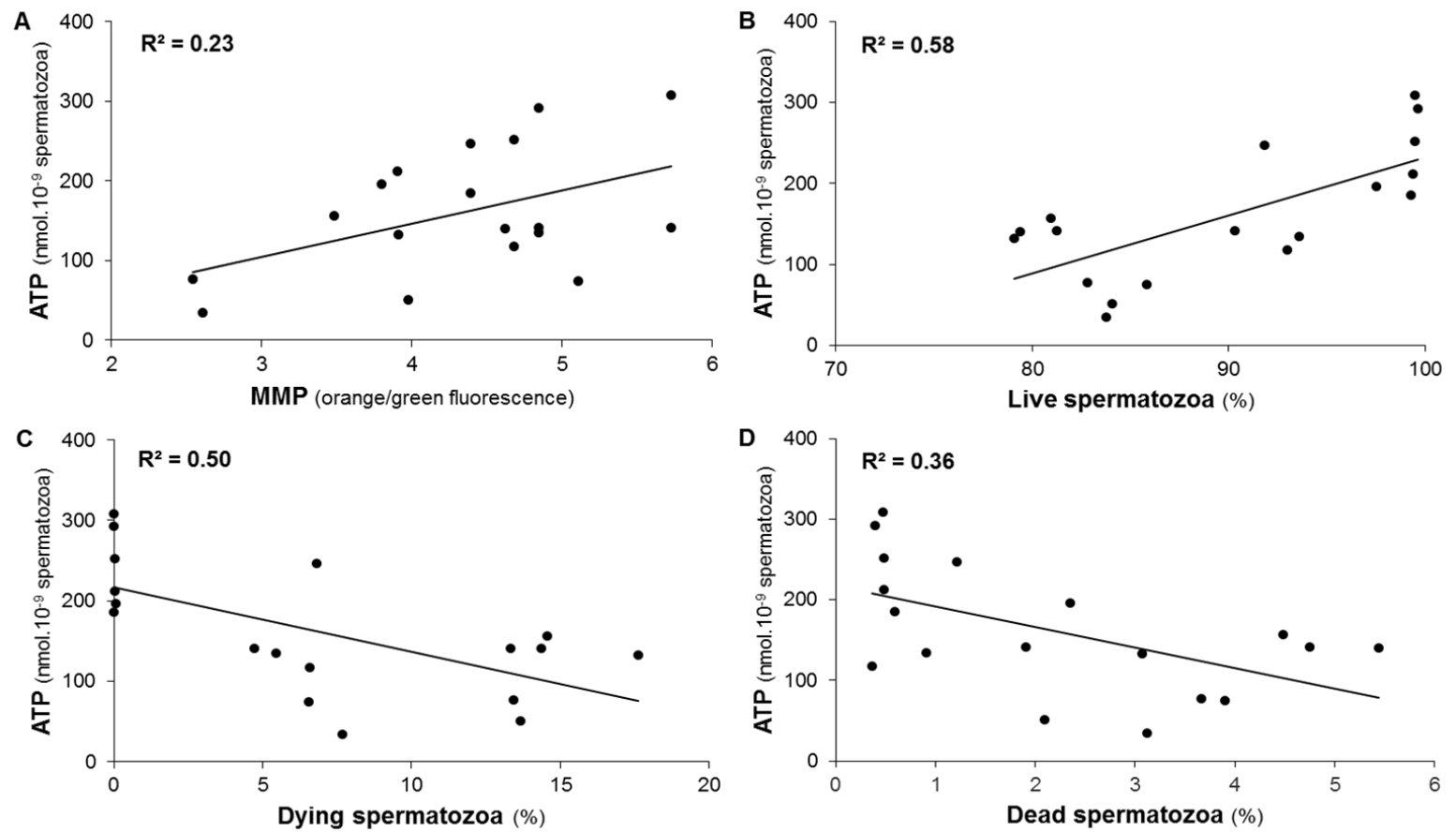

Figure 2 

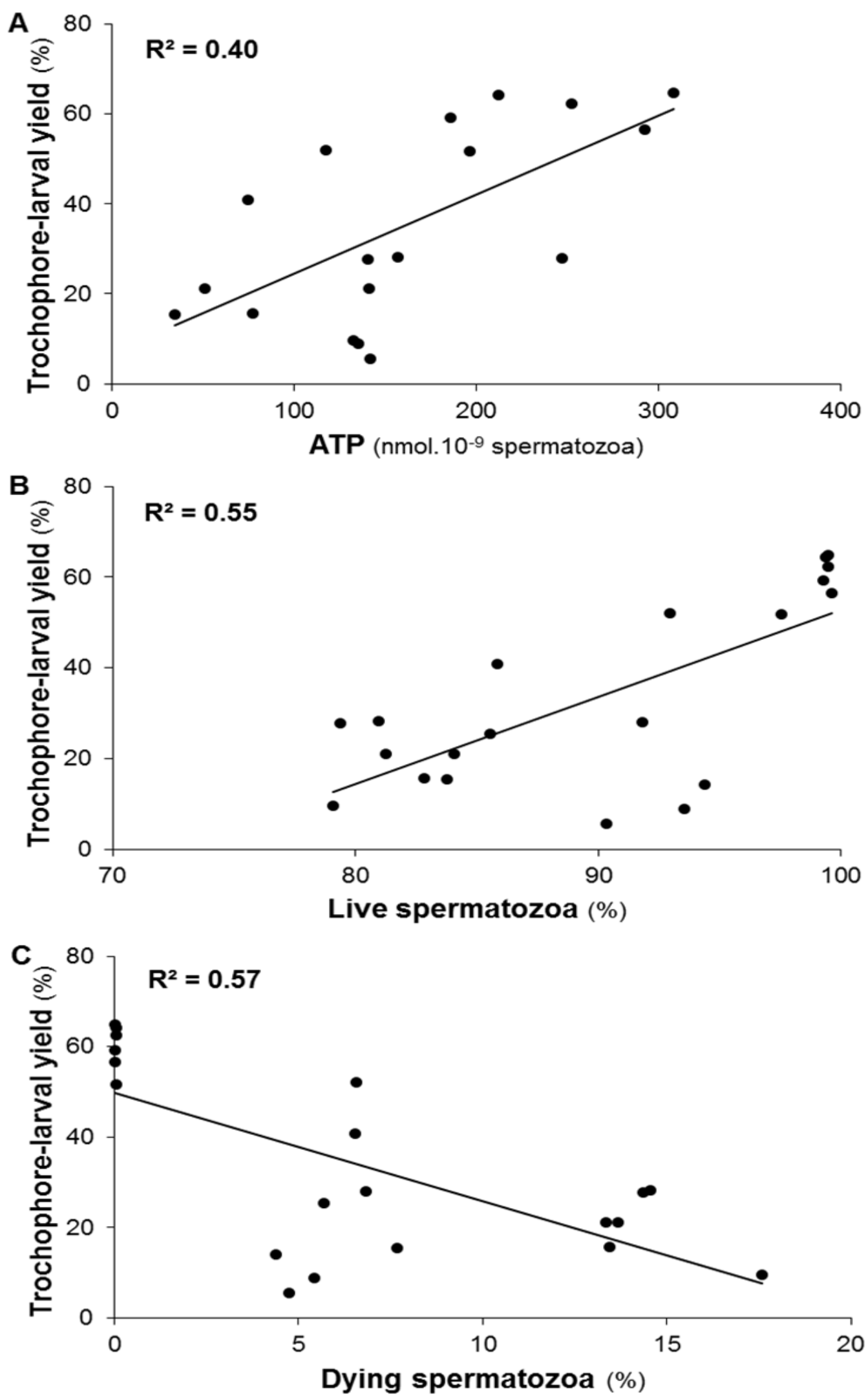

Figure 3 